\title{
Absorption, excretion, and retention of selenium from a high selenium yeast in men with a high intake of selenium
}

\author{
Susanne Bügel', Erik H. Larsen², Jens J. Sloth², Knut Flytlie ${ }^{3}$, \\ Kim Overvad ${ }^{4}$, Lars C. Steenberg ${ }^{5}$ and Sven Moesgaard ${ }^{5}$
}

'Department of Human Nutrition, University of Copenhagen, Frederiksberg, Denmark; ${ }^{2}$ Department of Chemistry, National Food Institute, Technical University of Denmark, Denmark and National Institute of Nutrition and Seafood Research, Bergen, Norway; ${ }^{3}$ Center Clinic, Vejle, Denmark; ${ }^{4}$ Department of Clinical Epidemiology, Aalborg Hospital and Aarhus University Hospital, and Department of Epidemiology and Social Medicine, University of Aarhus, Aarhus, Denmark; ${ }^{5}$ Pharma Nord Research Department, Vejle, Denmark

Abstract

Objective: The purpose of this study was to evaluate the pharmacokinetics of a single dose of selenium (Se) from yeast given to humans with a habitual long-term daily intake at a supra-nutritional level.

Methods: Twelve healthy males with a daily supplemental intake of $300 \mu \mathrm{g}$ Se as selenised yeast over 10 weeks were supplemented with a single dose of $327 \mu \mathrm{g}$ as stable ${ }^{77} \mathrm{Se}$ incorporated into selenised yeast manufactured by the same standardised process (SelenoPrecise ${ }^{\circledR}$, Pharma Nord, Denmark).

Results: Absorption of Se from ${ }^{77} \mathrm{Se}$-enriched yeast was $89 \pm 4 \%$ and the retention was $74 \pm 6 \%$. The ${ }^{77} \mathrm{Se}$ excretion from the single-dose was $47 \pm 15 \mu \mathrm{g}$ in urine and $37 \pm 13 \mu \mathrm{g}$ in faeces. The maximum, enriched ${ }^{77} \mathrm{Se}$ concentration in plasma was $9.8 \pm 1.5 \mu \mathrm{g} / \mathrm{l}$ and the time to maximum was 9.2 hours. The plasma halftime of ${ }^{77}$ Se was longer with increasing time; 1.7 days for the initial phase ( $1 / 2-2$ days), 3.0 days for the middle phase (2-3 days) and 11.1 days for the later phase (3-14 days).

Conclusion: The Se from the standardised Se-enriched yeast was well absorbed and retained in the body.

Keywords: selenium yeast; stable isotope; humans; pharmacokinetics; absorption; excretion

Received: 4 Oct. 2007; Revised: 14 Dec. 2007; Accepted: 7 Jan. 2008

$\mathrm{S}$ elenium (Se) intake in many European countries is relatively low (1) due to the low soil Se concentrations or poor bioavailability of soil Se for uptake into the plant roots in a great part of Europe. The recommended daily allowances of Se is $50 \mu \mathrm{g}$ for men and $40 \mu \mathrm{g}$ for women in the Nordic countries (2), and is based on saturation of the activity of glutathione peroxidase -3 (GSH-Px-3) in plasma. However, saturation of GSH-Px-3 occurs at a relatively low intake of $\mathrm{Se}(40 \mu \mathrm{g} / \mathrm{d})$ compared to the intake of Se needed to saturate GSH-Px-1 in erythrocytes $(60-80 \mu \mathrm{g} / \mathrm{d})$ or GSH-Px-1 in platelets $(100$ $110 \mu \mathrm{g} / \mathrm{d}$ ). Dietary Se intake may be sub-optimal with respect to prevention of disease, notably in populations of adults in the UK, parts of Europe and China, New Zealand and in the USA (1). There have been indications that certain forms of cancer might be prevented by intake of Se as selenised yeast (Se-yeast), in doses that are higher than required in order to saturate the selenoenzymes $(1$,
3). Recently, it has been hypothesised that Se intake in the range of $40-100 \mu \mathrm{g} / \mathrm{d}$ primarily has antioxidant and immune-strengthening effects, while intake in the range $200-500 \mu \mathrm{g} / \mathrm{d}$ has specific cancer-preventive properties (4). An intake of $\mathrm{Se}$ of this magnitude is, however, difficult to obtain from the diet in most parts of the world where Se content and bioavailability from soils is moderate or low.

Selenium can be found in a number of different Secontaining molecules (species), which are absorbed from the intestinal tract, but retained in different fractions depending on the species (5). Rat studies have shown that selenomethionine (Se-meth) is absorbed by an active transport mechanism, which is shared with methionine, while other species are absorbed by sharing an active transport system with other amino-acids, by simple diffusion or by Na-depending transport systems (6). Selenium is primarily excreted via urine and faeces. The 
amounts in urine and faeces have been shown to be of similar magnitude when Se intake is low (7). The most important factors that influence Se excretion are probably the amount and form of dietary intake and Se status of the individual. Whole-body retention studies in young women following oral administration of radioactive ${ }^{75} \mathrm{Se}-$ meth have shown that Se elimination is triphasic (8).

Few studies have made use of the stable isotope technique for measurement of Se absorption, excretion and retention in humans. To our knowledge, no study has previously been published on estimation of the absorption and retention of a single dose of Se-yeast in individuals with a supra-nutritional Se intake at the 300 $\mu \mathrm{g} /$ day level. The aims of this study were to measure the absorption, excretion and retention of Se contained in intrinsically labelled yeast in humans with a high habitual Se intake. The enriched stable isotope approach using ${ }^{77} \mathrm{Se}$-SelenoPrecise yeast was applied for the measurements of absorption, retention, and excretion. Furthermore, the pharmacokinetics in a real-life situation of long-term supplementation with Se was investigated.

\section{Materials and Methods}

\section{Study design}

The study was a single dose study with 12 healthy volunteers and was conducted as a pharmacokinetic study. Nine of the subjects were taking Se-supplements regularly and in an attempt to standardise Se intake, subjects were instructed to take $300 \mu \mathrm{g}$ Se as Se-yeast for ten weeks before entering the study. The stable ${ }^{77} \mathrm{Se}$ isotope was taken as intrinsically ${ }^{77} \mathrm{Se}$-labelled yeast under standardised, controlled conditions. Eleven blood samples were taken after administration of the stable isotope at baseline, after $30 \mathrm{~min}, 1,2,4,6,8,12,24,48$ and 72 hours. $24 \mathrm{~h}$ pooled urines were collected the day before and 3 days after, and faeces was collected the day before and for 5 days after ${ }^{77} \mathrm{Se}$ administration. Finally, blood, $24 \mathrm{~h}$ urine and faeces samples were collected after 14 days for six volunteers randomly selected prior to the beginning of the study.

\section{Subjects}

Twelve healthy males volunteered for the study (Table 1). The average age was 38 years (26-51 years), average body mass index $(\mathrm{BMI})$ was $25.0 \pm 2.3 \mathrm{~kg} / \mathrm{m}^{2}$, and mean fat mass $19.1 \pm 3.2 \%$ (Bio-electrical Impedance Analysis, Omron BF 302, Hoofddorp, Netherlands).

None of the volunteers had any major illness, was treated with medicine, had allergy to Paraaminobenzoic acid (PABA), practised sport at an elite level, or had participated in other clinical studies within a month before inclusion into the present study. The volunteers were examined by a physician, prior to inclusion into the
Table 1. Characteristics of the 12 human male volunteers at baseline

\begin{tabular}{lcc}
\hline & \multicolumn{2}{c}{ Mean } \\
\hline Age (years) & 37.7 & 8.4 \\
BMI $\left(\mathrm{kg} / \mathrm{m}^{2}\right)$ & 25 & 2.3 \\
Body fat $(\%)$ & 19.1 & 3.2 \\
$\mathrm{Hb}(\mathrm{g} / \mathrm{dl})$ & 15.7 & 0.8 \\
$\mathrm{Ht}(\%)$ & 49.8 & 2.5 \\
B-Se $(\mu \mathrm{g} / \mathrm{L})$ & 212 & 23 \\
$\mathrm{Hg}(\mu \mathrm{g} / \mathrm{L})$ & 1.6 & 0.9 \\
\hline
\end{tabular}

$\mathrm{BMI}=$ body mass index, $\mathrm{Hb}=$ haemoglobin, $\mathrm{Ht}=$ haematocrit, $\mathrm{B}-\mathrm{Se}=$ whole blood $\mathrm{Se}, \mathrm{Hg}=$ mercury.

study. Eight of the 12 volunteers were smokers. The average duration of smoking was $18.3 \pm 8.6$ years and the average number of cigarettes per day was $16.8 \pm 3.7$. The volunteers were assigned to an intake of $300 \mu \mathrm{g}$ Se as Seyeast for 10 weeks before entering the study. Nine of the volunteers had an even longer history of taking organic $\mathrm{Se}$ as Se-meth or Se-yeast, usually in amounts of approximately $100 \mu \mathrm{g} /$ day (mean intake (min-max) were $119 \mu \mathrm{g} / \mathrm{d}(62.5-225 \mu \mathrm{g} / \mathrm{d})$. Mean total plasma Se was $182 \pm 14 \mu \mathrm{g} / 1$ and mean whole blood Se was $213 \pm 23 \mu \mathrm{g} / 1$. The volunteers continued their habitual intake of food supplements, but were not allowed to take other Se containing products except the $300 \mu \mathrm{g}$ Se/day as Se-yeast. Table 1 shows the mean baseline whole blood Se and also baseline values of other selected biomarkers, which are all within normal range for a healthy population.

The study was approved by the local ethical committee (Fyn and Vejle County, Denmark, Ref. no 2000-0143) and was conducted in accordance with the Declaration of Helsinki (including amendments of Tokyo 1975, Venice 1983, Hong Kong 1989 and Sommerset West 1996). All participants signed an informed consent form.

\section{Test meal}

The stable isotope-labelled yeast was given together with a light meal after an overnight fast. The test meal consisted of one serving of müsli with $200 \mathrm{ml} \mathrm{milk}$ ( $1.5 \%$ fat), two slices toast with 10 gram of butter, marmalade, two slices of cheese and one cup of tea or coffee. Nutrient values were calculated using the Dankost $2000^{\circledR}$ dietary assessment software (Danish Catering Center, Herlev, Denmark) (9). The total energy in the meal was 2.9 MJ. Protein content was 16.1\%, lipid content was $29.3 \%$ and carbohydrate content was $54.6 \%$ of the total energy. The calculated content of $\mathrm{Se}$ in the meal was $8.4 \mu \mathrm{g}$.

\section{Preparation of selenium supplement}

The 10 weeks unlabelled run-in Se preparation used (SelenoPrecise ${ }^{\circledR}$, Pharma Nord, Denmark) was produced 
by a standardised procedure using a Pharmacopoeiacontrolled growth medium, as a source of carbon, nitrogen, micronutrients, and yeast of Saccharomyces cerevisiae (strain PN0056). The yeast was grown aerobically under controlled addition of sodium selenite $\left(\mathrm{Na}_{2} \mathrm{SeO}_{3}\right)$ with a natural $\mathrm{Se}$ isotope distribution (abundance of ${ }^{77} \mathrm{Se}=7.63 \%$ ). The yeast metabolised more than $95 \%$ of the added Se, which was incorporated into a range of organic Se-species. The predominant species was Se-meth $(81 \%$ of all separated and quantified Se species in the enzymatic hydrolysate or corresponding to $60 \%$ of the total Se content in the yeast), and the residual selenite $\left(\mathrm{SeO}_{3}^{2-}\right)$ in the yeast was less than $1 \%$ as determined by enzymolysis and HPLC-ICP-MS (10). The yeast was harvested, washed, pasteurised, spray dried and processed to tablets. The potency of $300 \mu \mathrm{g}$ per tablet was confirmed by analyses to lie within $\pm 5 \%$ of the target value. The Se yeast, its speciation and long-term bioavailability at dose-levels of 100, 200 and $300 \mu \mathrm{g} /$ day has been described in further detail by Larsen et al (11).

The intrinsically labelled single dose of ${ }^{77} \mathrm{Se}-$ SelenoPrecise ${ }^{\circledR}$ (Pharma Nord, Denmark) contained $329.0 \mu \mathrm{g}$ total $\mathrm{Se}$, which included $327 \pm 9 \mu \mathrm{g}$ of ${ }^{77} \mathrm{Se}$ (Chemgas, Boulogne, France) and was produced by the same procedure as indicated above, except that the isotopically enriched $\mathrm{Na}_{2} \mathrm{SeO}_{3}$ used as substrate contained ${ }^{77} \mathrm{Se}$ at $99.3 \%$. Furthermore, the yeast was freezedried instead of spray-dried. The isotopic composition and concentration of $\mathrm{Se}$ in the ${ }^{77} \mathrm{Se}$-enriched yeast was characterised by mass spectrometric analyses to allow for an accurate administration of the isotope. Speciation analyses showed that Se-meth amounted to $82 \%$ of all separated and quantified Se species in the enzymatic hydrolysate, or to $53 \%$ of the total Se content in the yeast. The content of $\mathrm{SeO}_{3} 2^{-}$was less than $1 \%(10)$. The ${ }^{77} \mathrm{Se}-$ SelenoPrecise yeast was filled into hard gelatine capsules by single weighing of the individual capsules to achieve $327 \mu \mathrm{g}{ }^{77}$ Se per dose.

\section{Sample collection and preparation}

Total faecal samples were collected from the 12 volunteers in acid washed plastic containers for one day before administration of the ${ }^{77} \mathrm{Se}$-yeast and for 5 days thereafter, and again for one day after 14 days for 6 of the 12 volunteers. To control the origin in time of the collected faeces samples (12), four different radio-opaque faecal markers (Medi-Fakt, Göteborg, Sweden) were consumed in hard gelatine capsules $(3 \times 20$ markers per day taken at breakfast, lunch and dinner), one day prior to and during the faecal collection. A total of 60 markers represented one day. One shape of faecal markers were given on the two days prior to the test meal, another shape of faecal markers were given together with the test meal and a third shape of markers were given to the other two main meals on the test day. A fourth shape of markers was given the following days. This made possible to distinguish between faeces from the day before, from the time of intake, from the first day and the 5 days following administration of the isotope. The faeces samples were pooled accordingly. 24-h urine was collected the day before and 3 days after ${ }^{77} \mathrm{Se}$ administration and again after 14 days for six of the volunteers. To control complete collection of urine PABA tablets $(3 \times 80 \mathrm{mg})$ were consumed at the same days as the urine collection (13).

Blood for plasma analyses was drawn at $-1 / 2$ (baseline), $1 / 2,1,2,4,6,8,12,24,48,72$ hours and for half of the group additionally after 14 days after intake of the stable isotope yeast preparation. Blood was drawn into heparin tubes (Becton-Dickinson, NJ, USA). The blood was centrifuged at room temperature for 10 minutes at $3000 \mathrm{rpm}$, plasma was pipetted into plastic vials and kept at $-20^{\circ} \mathrm{C}$ until the time of analysis of plasma Se. At baseline $(-1 / 2 h)$ blood was also drawn into a heparin tube and kept at $-20^{\circ} \mathrm{C}$ until analysis of trace elements and creatinine.

\section{Analytical methods}

Faeces samples were freeze-dried, homogenised, microwave digested using nitric acid (14) and then pooled according to the content of faecal markers (15). Prior to Se analysis, the plasma and urine samples and the digested faeces samples were diluted using an aqueous diluent containing $0.5 \%$ Triton X-100, $2 \%$ nitric acid and $3 \%$ methanol. An ELAN 6100 ICP-MS instrument (Perkin-Elmer SCIEX, Concord, Ont., Canada), which was equipped with a dynamic reaction cell (DRC), was used for the interference-free Se measurements as the DRC removed the argon dimer interferences (16). Selenium was detected in all samples as ${ }^{76} \mathrm{Se},{ }^{77} \mathrm{Se}$ and as ${ }^{80} \mathrm{Se}$ and quantified by the method of standard additions (17).The degree of enrichment in ${ }^{77} \mathrm{Se}$, was estimated from the total amount of ${ }^{77} \mathrm{Se}$ (supplemented plus endogenous) minus the endogenous amount of ${ }^{77} \mathrm{Se}$. The total amount of endogenous Se with a natural isotopic composition was quantified from measurement of ${ }^{80} \mathrm{Se}$, the abundance of which was not altered by the administered single dose of $99.3 \%$ pure ${ }^{77} \mathrm{Se}$ isotope. The total Se content in the samples was calculated as the sum of the ${ }^{77} \mathrm{Se}$-enriched and endogenous concentrations of Se. The minimum detectable increase in ${ }^{77} \mathrm{Se}$ was $0.38 \mu \mathrm{g} /$ $1,0.58 \mu \mathrm{g} / \mathrm{l}$ and $15 \mu \mathrm{g} / \mathrm{kg}$ for plasma, urine and faeces, respectively. The reproducibility was estimated by random duplicate analyses and the accuracy by analysis of the reference materials Seronorm Serum (Nycomed Pharma Dianostics, Oslo, Norway) and BCR CRM 185 Bovine Liver (BCR, Institute for Reference Materials and Measurements, Geel, Belgium) in parallel with samples (17). Urine was also analysed for PABA (13) and 
creatinine (Jaffé Method, Roche Diagnostics GmbH, Mannheim, Germany) was measured in urine and plasma.

\section{Statistics and calculation}

The enriched concentrations of ${ }^{77} \mathrm{Se}$ in the individual samples of plasma, urine and faeces were integrated to yield the amount of the isotope that appeared in these biological samples from each human volunteer (17). Only faecal samples, which contained radio-opaque markers, originated from the meal with the ${ }^{77} \mathrm{Se}$-yeast administration, or with markers taken later than this, were included. ${ }^{77}$ Se mass balances were established and based on all days of faecal and urinary collections. The total ${ }^{77} \mathrm{Se}$ content of the faecal and urinary samples was analysed and excretion of faecal radio-opaque markers was used to calculate average daily excretion. The apparent absorption of ${ }^{77} \mathrm{Se}$ was calculated as the difference between the intake of ${ }^{77} \mathrm{Se}$ tracer and the amount of tracer from this intake found in faeces during the collection period. The retention of ${ }^{77} \mathrm{Se}$ was calculated from the difference between the administered amount of ${ }^{77} \mathrm{Se}$ and the sum of faecal and urinary excretions during the collection period.

One-way ANOVA was conducted for the data at different time-points. The significance level was predefined as $95 \%$. Correlation between creatinine clearance and total urine ${ }^{77} \mathrm{Se}$ was examined in a scatterplot.

\section{Results}

\section{Compliance}

Compliance was assessed directly by supervising the intake of the ${ }^{77} \mathrm{Se}$-preparation. On the day of isotope administration the diet was standardised. The rest of the time participants were asked about compliance with the protocol when returning specimens. Compliance for the ${ }^{77}$ Se preparation was $100 \%$. Compliance for the 10 weeks daily intake of $300 \mu \mathrm{g}$ Se as SelenoPrecise yeast before the study start was $90 \%$ or better, which was controlled by interviewing each participant. One of the participants reported that he forgot to take one capsule of the radio-opaque faecal markers (day five in the collection period), the rest of the participants had $100 \%$ compliance. One of the participants missed one blood drawing because of illness (diarrhoea and vomiting at day 4). The completeness of urine collection was controlled by analysis of PABA, which showed a full recovery of (mean and SD) 108\% $\pm 6.6 \%$. Radio-opaque faecal markers controlled the complete collection of faeces originating from the day of ${ }^{77} \mathrm{Se}$ administration. The ${ }^{77} \mathrm{Se}$ preparation was taken at the same time as the 20 identifiable radio-opaque faecal markers. Retrieval of at least 18 of 20 markers was considered as a full sample collection. All the participants were found to have complete faeces collection. As an extra control of the urine and faeces collection the participants were asked every day for any irregularities in their collection. Three subjects did not collect faeces on day 4 and 5 due to either irregular defecation or constipation. Other reported irregularities were negligible.

\section{Selenium pharmaco-dynamics}

The apparent absorption of Se from a single dose of 327 $\mu \mathrm{g}{ }^{77} \mathrm{Se}$ as Se yeast was found to be $88.7 \pm 3.9 \%$ in the Danish men with a high habitual Se intake (Table 2). The mean ${ }^{77} \mathrm{Se}$ excretion from the single dose over the collection days in urine and faeces was $47.4 \pm 14.8 \mu \mathrm{g}$ and $37.1 \pm 12.7 \mu \mathrm{g}$, respectively. The ${ }^{77} \mathrm{Se}$ excretion in urine is shown in Fig. 1. The ${ }^{77}$ Se tracer percentage in faeces over the period is shown in Fig. 2. The mean ${ }^{77} \mathrm{Se}$ retention at day 4 was $242 \pm 19 \mu \mathrm{g} / \mathrm{d}$, which corresponds to $74.2 \pm$ $5.9 \%$ of the ${ }^{77} \mathrm{Se}$ intake. The results for the mean ${ }^{77} \mathrm{Se}$ plasma concentrations during the $72 \mathrm{~h}$ following administration of ${ }^{77} \mathrm{Se}$ are shown in Fig. 3. The mean ${ }^{77} \mathrm{Se}$ plasma concentration at day 14 was $2.28 \pm 0.18 \mu \mathrm{g} / \mathrm{l}(\mathrm{n}=$ 6) (not shown). The maximum ${ }^{77} \mathrm{Se}$ concentration in plasma was reached after six hours $(n=1)$, eight hours

Table 2. Intake, absorption, excretion and retention of $327 \mu \mathrm{g}{ }^{77} \mathrm{Se}$ administered as a single dose to 12 men with a habitual high intake of Se. The values are based on urinary and faecal excretion from days 1-3 after administration of ${ }^{77} \mathrm{Se}$. Values are given as median values with $10-90 \%$ percentiles and also as means \pm standard deviation. Values are further given as $\%$ of the ingested dose with $10-90 \%$ percentiles and also \pm standard deviation.

\begin{tabular}{|c|c|c|c|c|}
\hline & \multicolumn{2}{|c|}{$\mu g$} & \multicolumn{2}{|c|}{$\%$} \\
\hline & Median (10-90 pct) & Mean (SD) & Median (10-90 pct) & Mean (SD) \\
\hline Intake & - & 327 & - & 100 \\
\hline Absorption & $284(28 I-308)$ & $290(13)$ & $87(86-94)$ & $89(4)$ \\
\hline Retention & $248(220-258)$ & $242(19)$ & 76 (67-79) & $74(6)$ \\
\hline Faecal excretion & $43(19-46)$ & $37(13)$ & $13(6-14)$ & II (4) \\
\hline Urinary excretion & $44(36-61)$ & $47(15)$ & $14(11-19)$ & $15(5)$ \\
\hline
\end{tabular}




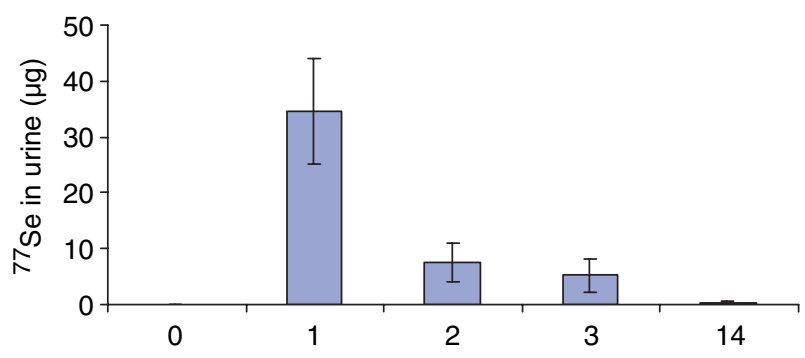

Fig. 1. Mean tracer in urine from the single ${ }^{77} \mathrm{Se}$ dose detectable before administration (day 0 ) of a single oral dose and at day 1, 2, 3, and 14 after tracer administration $($ Mean \pm SD; Day 0 to 3: $n=12$; Day 14: $n=6$ ).

$(\mathrm{n}=7)$, and 12 hours $(\mathrm{n}=4)$. The mean $\mathrm{T}_{\max }$ was 9.17 hours (median $\mathrm{T}_{\max }=8 \mathrm{~h}$ ) and the mean ${ }^{77} \mathrm{Se}$ plasma $\mathrm{C}_{\max }$ from the single dose was $9.78 \pm 1.53 \mu \mathrm{g} / \mathrm{l}$. The halftime of ${ }^{77} \mathrm{Se}$ in plasma $(\mathrm{n}=6)$ was longer with increasing time; 1.7 days for the initial phase ( $1 / 2-2$ days), 3.0 days for the middle phase (2-3 days) and 11.1 days for the later phase (3-14 days). The mean plasma Se concentration (not shown) varied slightly, but statistically non-significant, between days $0-14$.

Creatinine clearance was calculated based on serum creatinine, $24 \mathrm{~h}$ urine creatinine excretion and on diuresis within $24 \mathrm{~h}$. The urinary creatinine clearance was within the normal range for the age group $(0.8-2.8 \mathrm{ml} / \mathrm{s})$. No relation was found between creatinine clearance and total urine ${ }^{77} \mathrm{Se}$ excretion (data not shown).

\section{Side effects}

One subject reported pharyngitis for three days, one had hay fever for one day, and one had diarrhoea and vomiting for one day. None of these reactions were associated with the yeast-based Se supplements. No other adverse effects were observed. Two of the subjects took

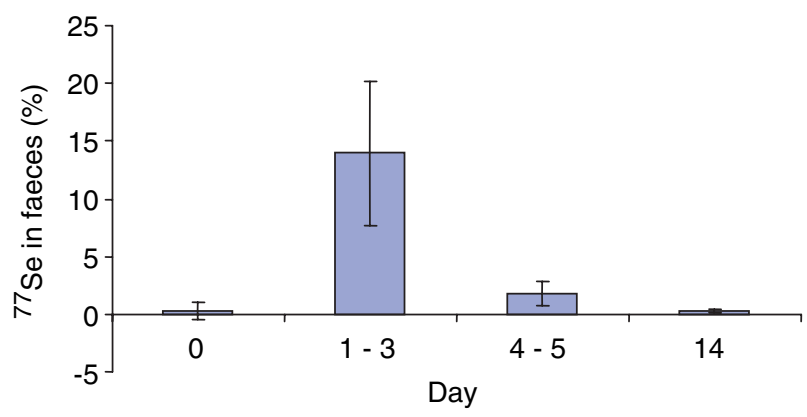

Fig. 2. Mean tracer in faeces from the single ${ }^{77} \mathrm{Se}$ dose as percentage of the total selenium detectable before marker excretion (day 0 ) and in samples of day $1-3,4-5$, and day 14 after tracer excretion. The periods were pooled according to the markers taken simultaneous with the single dose. The data are presented as mean values $\pm \mathrm{SD}$ with 12 specimens at day 0 and day $1-3$. The data of day $4-5$ and day 14 included 9 and 6 specimens, respectively.

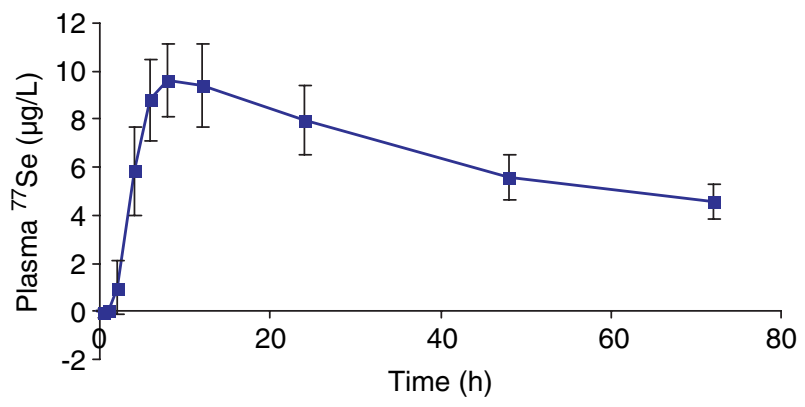

Fig. 3. Mean plasma ${ }^{77}$ Se tracer concentration $(\mu \mathrm{g} / \mathrm{L})$ in 12 human volunteers given a single oral dose of $327 \mu \mathrm{g}{ }^{77} \mathrm{Se}$ as Selenium yeast together with a light meal after an overnight fast (Mean $\pm \mathrm{SD} ; \mathrm{n}=12)$.

medication during the study. One received treatment with penicillin due to pharyngitis in the beginning of the collection period, and one had a short attack of hay fever and took anti-histamine.

\section{Discussion}

Intake of Se in the range of $200-500 \mu \mathrm{g} / \mathrm{d}$ has been suggested to be anticarcinogenic (3). However, intakes of this magnitude are difficult to obtain from the diet and therefore there might be a need for safe and efficient supplements. A number of studies have compared the metabolic fate of inorganic Se (selenite and selenate) or SeMeth given in foods or as supplement $(18,19)$. These previous studies have shown that besides the chemical form of ingested Se and Se status of the individual, other factors e.g. age, alcohol consumption, smoking and hormonal therapy might also affect Se metabolism and status $(20,21)$.

The high absorption of Se observed in the present study in participants with a high habitual Se intake is in agreement with previous studies $(7,18,22)$. The absorbed fraction of Se from different $\mathrm{Se}$ yeasts is known to be large, but the absorption and bioavailability of Se vary between different batches of Se-yeast (23), which makes comparisons of results from studies using different Seyeast difficult. A comparative study showed, that the human absorption of Se from different Se-yeasts, as expressed by plasma Se concentrations, depended on baseline Se status or on Se speciation in the yeast-based preparations used (24). Other research groups have also shown that the whole-body Se content is a critical factor affecting the homeostatic metabolism of newly ingested Se $(18,19,25,26)$, and the reason is probably that some adaptation to different intakes occur. Some studies have shown that the fractional absorption actually increases by increasing the intake of Se $(19,25)$ and although this study was not designed to compare absorption at high and low intakes of Se, this would suggest that absorption is not a major regulator of homeostasis of Se. 
Regarding the Se speciation of the SelenoPrecise yeast, analysis by HPLC-ICPMS following enzymatic hydrolysis showed, that SeMeth constituted $60 \%$ of the total Se content in the yeast (10). Selenocysteine was not detected in the yeast, which was in accordance with the fact that the yeast genome does not include the necessary codon for its biosynthesis (27). The remainder of the Se was present as more than 30 unknown Se-species of low abundance whereas selenite and SeMeth Se-oxide were present at less than $1 \%$ of the total Se content in the yeast. The identity of Se species, which correspond to the non-extractable fraction (26\%), remained unknown (10). A separate study characterised the Se species contained in the ${ }^{77} \mathrm{Se}-$ SelenoPrecise yeast used in this study (10). The results showed that approximately $55 \%$ of the total Se in the yeast was present as SeMeth, which was similar to the value found for the SelenoPrecise yeast.

Selenium excretion occurs primarily via urine and faeces (8). Levels of faecal excretion of Se have been reported to be similar to levels of urinary Se excretion when dietary levels of Se are not excessive. In the present study we observed a relatively low excretion of Se from urine $(15 \%)$ and faeces $(11 \%)$ of a single ${ }^{77}$ Se dose during the first 4 days. The majority of the urinary $\mathrm{Se}$ was excreted within the first 24 hours after intake of ${ }^{77} \mathrm{Se}$ and thereafter excretion was reduced to low levels. The same tendency was observed for the faecal excretion, although the ${ }^{77}$ Se faecal excretion remained high until 48-72 hours after the single ${ }^{77}$ Se supplementation (results not shown). This might indicate entero-hepatic recirculation in agreement with previous studies with SeMeth (28) showing that a significant proportion $(46 \%)$ of the amount leaving the liver was found to re-enter the intestines.

The analytical results of plasma and urine samples from day 1 to day 14 showed that the elimination of ${ }^{77} \mathrm{Se}$ was not complete and that the plasma concentration was approximately $20 \%$ of the initial peak plasma concentration. At day 14 the ${ }^{77}$ Se excretion was still on-going, as the ${ }^{77} \mathrm{Se}$ concentration in urine and faeces had not returned to baseline. The total amount of ${ }^{77} \mathrm{Se}$ excreted at day 14 was $1.61 \mu \mathrm{g}, 48 \%$ of which was excreted via kidneys to urine and $52 \%$ was excreted via faeces.

A kinetic model for SeMeth was proposed by Patterson et al (29) who suggested that SeMeth is extensively recirculated and passed through liver, pancreas and peripheral tissues many times before being excreted. This would explain that labelled Se is still found in faeces and urine 2 weeks after administration. The same was observed a year after labelling of body pools by Veillon et al (30). In the present study we also observed a high excretion of total Se in both urine and faeces (data not shown), which reflects the high intake of Se in this group of people and is in accordance with results from other studies feeding high amounts of Se (19). We cannot, however, from our data, conclude if this is caused by adaptation to the higher intake. In the study by Hawkes (19) it was observed that when the intake of Se was increased from normal $(47 \mu \mathrm{g} / \mathrm{d})$ to high $(297 \mu \mathrm{g} / \mathrm{d})$, the urinary and faecal excretion of Se almost doubled, while deposition in muscles increased by approximately $25 \%$ during the 99 days with high Se intake. It is likely that the high intake in our study has changed the distribution of Se in the body.

According to Clark et al. (3) steady state in plasma-Se with a supplemented daily dose of $200 \mu \mathrm{g}$ Se as Se yeast was reached after 6-9 months, and Clark et al. observed a plateau of approximately $190 \mu \mathrm{g} / \mathrm{l}$ after one year and for the next 9 years of his observational period. When $300 \mu \mathrm{g}$ Se per day of the same standardised yeast (SelenoPrecise) was given to a UK cohort $(\mathrm{n}=103)$ for 6 months the mean plasma-Se was raised from $92 \pm 20 \mu \mathrm{g} / \mathrm{l}$ to $233 \pm 54$ $\mu \mathrm{g} / 1$ (11). In the present study, the plasma Se concentration was $182 \pm 14 \mu \mathrm{g} / \mathrm{l}$ after 10 weeks supplementation with $300 \mu \mathrm{g} \mathrm{Se} / \mathrm{d}$. When $0,100,200$ or $300 \mu \mathrm{g} / \mathrm{day}$ of the same standardised yeast was given to a Danish cohort $(n=49)$ for two years, the Se-whole-blood response was linearly proportional to the total daily intake. The mean blood-Se level in the $300 \mu \mathrm{g}$ intake group, which was $441 \pm 132 \mu \mathrm{g} / \mathrm{l}$, was in steady state after 2 years supplementation (11). The blood-Se concentration was $213 \pm 23$ $\mu \mathrm{g} / \mathrm{l}$, in the present study, after 10 weeks administration of an identical Se-yeast. The 10 weeks pre-supplementation in the present study with $300 \mu \mathrm{g}$ Se/day is therefore not sufficiently long to fully attain steady state. This is likely to have affected the validity of the results.

In the present study, the mean ${ }^{77} \mathrm{Se}$ plasma maximum concentration was $9.77 \pm 1.53 \mu \mathrm{g} / 1$ where the median $\mathrm{T}_{\max }$ was 8 hours and the mean $\mathrm{T}_{\max }$ was found at 9.17 hours. The $T_{\max }$ results observed in our study were in agreement with a previously reported $\mathrm{T}_{\max }$ at approximately 8 hours after supplementation of $100 \mu \mathrm{g}{ }^{74}$ selenate (18). Finley (18) found a plasma maximum concentration of approximately $5.3 \mu \mathrm{g} / \mathrm{l}$, which was considerably lower than the plasma maximum observed in the present study, but this is probably a reflection of the chemical form of Se given, as well as the dose. Higher plasma concentrations have been observed in studies feeding SeMeth, compared to other chemical forms of Se $(31,32)$.

The mean plasma Se concentration observed in this study was considerably higher than values reported in unsupplemented Danish subjects; 75-95 $\mu \mathrm{g} / 1$ (14, 33), but was closer to results reported in other studies, which reported plasma concentrations from $111-190 \mu \mathrm{g} / 1$ in humans supplemented with 100-200 $\mu \mathrm{g}$ Se yeast $(3,34)$. This confirms that the subjects did take the supplements.

A number of factors might have affected the results obtained in this study, among these are the fact that although our subjects' year-long high Se intakes, the Se species and amounts of intakes differed among the subjects and the 10 week run-in period obviously was 
not sufficient to obtain steady-state. Furthermore, 8 of our subjects were current smokers and this as well might have affected the results as some studies have indicated that smoking might affect Se status (20). We think, however, that for the purpose of this study these factors have only minor effects.

\section{Conclusion}

In conclusion, the absorption and three days retention in Danish men with a high habitual Se intake was found to be high as investigated by the stable enriched isotope approach using a single dose of ${ }^{77}$ Se-labelled SelenoPrecise yeast.

\section{Acknowledgement}

We thank the CRO, Narayana Research, Stumpedyssevej 13, 2970 Horsholm, Denmark, who monitored this study. Also thanks to the volunteers who participated in the study for their collaboration and enthusiasm. Finally, the authors wish to thank PharmaNord, Vejle, Denmark who financed the project.

\section{References}

1. Rayman MP. The importance of selenium to human health. Lancet 2000; 356: 233-41.

2. Sandström B, Aro A, Becker W, Lyhne N, Pedersen JI, Porsdottir I, eds. Nordiska Näringsrekommendationer 1996. Nord 28.

3. Clark LC, Combs GF Jr, Turnbull BW, Slate EH, Chalker DK, Chow J, et al. Effects of selenium supplementation for cancer prevention in patients with carcinoma of the skin. A randomized controlled trial. Nutritional Prevention of Cancer Study Group. JAMA 1996; 276: 1957-63.

4. Rayman MP. The argument for increasing selenium intake. Proc Nutr Soc 2002; 61: 203-15.

5. Hommeren OJ. En sammenliknede absorpsjonsstudie av to organisk bundne selenpreparater og placebo. Tidsskr Nor Lægeforen 1990; 110: 3350-1.

6. Fairweather-Tait SJ. Bioavailability of selenium. Eur J Clin Nutr 1997; 51 Suppl 1: S20-3.

7. Daniels LA. Selenium metabolism and bioavailability. Biol Trace Elem Res 1996; 54: 185-99.

8. Hansen JC, Overvad K, Tarp U, Thorling EB. Selen. En almen biologisk oversigt. Ugeskr Læger 1985; 147: 1911-22.

9. Møller ASE. The Composition of Foods. Mørkhøj, Denmark, Levnedsmiddelstyrelsen (The National Food Agency), 1996

10. Larsen EH, Sloth J, Hansen M, Moesgaard S. Selenium speciation and isotope composition in Se-77-enriched yeast using gradient elution HPLC separation and ICP-dynamic reaction cell-MS. J Anal Atom Spectrom 2003; 18: 310-6.

11. Larsen EH, Hansen M, Paulin H, Moesgaard S, Reid DM, Rayman MP. Speciation and bioavailability of selenium in yeastbased intervention agents used in cancer chemoprevention studies. J Assoc Off Anal Chem 2004; 87: 225-32.

12. Branch WJ, Cummings JH. Comparison of radio-opaque pellets and chromium sesquioxide as inert markers in studies requiring accurate faecal collections. Gut 1978; 19: 371-6.

13. Bingham S, Cummings JH. The use of 4-aminobenzoic acid as a marker to validate the completeness of $24 \mathrm{~h}$ urine collections in man. Clin Sci 1983; 64: 629-35.
14. Bugel SH, Sandstrom B, Larsen EH. Absorption and retention of selenium from shrimps in man. J Trace Elem Med Biol 2001; 14: 198-204.

15. Sandstrom B, Bugel S, McGaw BA, Price J, Reid MD. A high oat-bran intake does not impair zinc absorption in humans when added to a low-fiber animal protein-based diet. J Nutr 2000; 130: 594-9.

16. Sloth JJ, Larsen EH. The application of inductively coupled plasma dynamic reaction cell mass spectrometry for measurement of selenium isotopes, isotope ratios and chromatographic detection of selenoamino acids. J Anal Atom Spectrom 2000; 15: 669-72.

17. Sloth JJ, Larsen EH, Bugel SH, Moesgaard S. Determination of total selenium and Se in isotopically enriched human samples by ICP-dynamic reaction cell-MS. J Anal Atom Spectrom 2003; 18: 317-22.

18. Finley JW. The Retention and Distribution by Healthy Young Men of Stable Isotopes of Selenium Consumed as Selenite, Selenate or Hydroponically-Grown Broccoli Are Dependent on the Isotopic Form. J Nutr 1999; 129: 865-71.

19. Hawkes WC, Alkan FZ, Oehler L. Absorption, distribution and excretion of selenium from beef and rice in healthy North American men. J Nutr 2003; 133: 3434-42.

20. Luty-Frackiewicz A, Jethon Z, Januszewska L. Effect of smoking and alcohol consumption on the serum selenium level of Lower Silesian population. Sci tot environ 2002; 285: 89-95.

21. Arnaud J, Akbaraly NT, Hininger I, Roussel AM, Berr C. Factors associated with longitudinal plasma selenium decline in the elderly: The EVA Study. J Nutr Biochem 2007; 18: 482-7.

22. Finley JW. The absorption and tissue distribution of selenium from high- selenium broccoli are different from selenium from sodium selenite, sodium selenate, and selenomethionine as determined in selenium-deficient rats. J Agric Food Chem 1998; 46: 3702-7.

23. Moesgaard S, Morrill R. The Need for Speciation to Realise the Potential of Selenium in Disease Prevention. In: Ebdon Les, Pitts Les, Cornelis Rita, Crews Helen, Donard OFX, Quevauviller Philippe, eds. Trace Element Speciation for Environment, Food and Health. Cornwall, UK: MPG Books Ltd; 2001. p. 261-84.

24. Clausen J, Nielsen SA. A comparison of ten selenium supplementation products. Med Biol 1988;305-314.

25. Finley JW, Duffield A, Ha P, Vanderpool RA, Thomson CD. Selenium supplementation affects the retention of stable isotopes of selenium in human subjects consuming diets low in selenium. Br J Nutr 1999; 82: 357-60.

26. Levander OA, Sutherland B, Morris VC, King J. Selenium balance in young men during selenium depletion and repletion. Am J Clin Nutr 1981; 34: 2662-9.

27. Kryukov GV, Kryukov VM, Gladyshev VN. New mammalian selenocysteine-containing proteins identified with an algorithm that searches for selenocysteine insertion sequence elements. J Biol Chem 1999; 274: 33888-97.

28. Swanson CA, Patterson BH, Levander OA, Veillon C, Taylor PR, Helzlsouer K, et al. Human [74Se]selenomethionine metabolism: a kinetic model. Am J Clin Nutr 1991; 54: 917-26.

29. Patterson BH, Zech LA, Swanson CA, Levander OA. Kinetic Modeling of selenium in humans using stable isotope tracers. J Trace Elem Electrolytes Health Dis 1993; 17: 117-20.

30. Veillon C, Patterson KY, Button LN, Sytkowski AJ. Selenium utilization in humans - a long-term, self-labeling experiment with stable isotopes. Am J Clin Nutr 1990; 52: 155-8.

31. Thomson CD, Burton CE, Robinson MF. On supplementing the selenium intake of New Zealanders 1. Short experiments with large doses of selenomethionine. Br J Nutr 1978; 39: 579 87. 
32. Thomson CD, Robinson MF. Urinary and fecal excretions and absorption of a large supplement of selenium: superiority of selenate over selenite. Am J Clin Nutr 1986; 44: 659-63.

33. Thorling EB, Overvad K, Geboers J. Selenium Status In Europe-Human Data A Multicenter Study. Ann Clin Res 1986; 18: 3-7.

34. Neve J. Human selenium supplementation as assessed by changes in blood selenium concentration and glutathione peroxidase activity. J Trace Elem Med Biol 1995; 9: 65-73.

\section{Susanne Bügel}

Department of Human Nutrition, The Royal Veterinary and Agricultural University,

Rolighedsvej 30, 1958 Frederiksberg C, Denmark

Phone: +45 - 35282490

Fax: +45-35282469;

Email:shb@kvl.dk

This project was financed by Pharma Nord, Vejle, Denmark 